\title{
LIBERDADE RELIGIOSA E CONFLITOS RELIGIOSOS NO AMBIENTE DE TRABALHO
}

\section{RELIGIOUS FREEDOM AND RELIGIOUS CONFLICT IN THE WORKPLACE}

\author{
${ }^{1}$ Isabelly Cristinny Gomes Gaudêncio \\ ${ }^{2}$ Aldo Cesar Filgueiras Gaudencio
}

\section{RESUMO}

O presente artigo se propôs a analisar o direito de acomodação da liberdade religiosa no ambiente de trabalho. Ainda nesse cenário, foram analisados os conflitos religiosos que podem ser suscitados nas relações de trabalho. Assim, qualquer afronta ao direito de liberdade religiosa sem motivo plausível, estar-se-á diante de uma afronta dos mais elementares direitos fundamentais. Diante disso, o artigo utilizar-se-á como emprego metodológico a pesquisa bibliográfica e o método de estudo o dedutivo, tendo em vista que o presente artigo parte da compreensão da regra geral para os casos específicos.

Palavras-chave: Liberdade religiosa; conflitos religiosos; ambiente de trabalho

\begin{abstract}
This article proposes to analyze the accommodation right of religious freedom in the workplace. Even in this scenario, the religious conflicts that can be raised in labor relations were analyzed. Thus, any affront to the right to religious freedom without any plausible reason, will be, in front of an affront of the most basic fundamental rights. Thus, the article will be used as a methodological job bibliographical research and the study of the deductive method, given that this Article of the understanding of the general rule for specific cases.
\end{abstract}

Keywords: Religious freedom; religious conflicts; desktop

\footnotetext{
${ }^{1}$ Mestranda em direito e desenvolvimento sustentável pelo Centro Universitário de João Pessoa (UNIPÊ), João Pessoa, Paraíba, Brasil. Email: tutortreinamneto@gmail.com

${ }^{2}$ Doutorando e mestre em direito civil pela Universidade de Coimbra (UC), Coimbra, Portugal. Email:

aldogaudencio@yahoo.com.br
} 


\section{INTRODUÇÃO}

Os conflitos religiosos relacionados com o exercício da liberdade religiosa se desenrolam em palcos variados. As relações de trabalho constituem um campo particularmente propício para o desenvolvimento de conflitos relacionados com a manifestação do fenômeno religioso.

Trata-se de um tema antigo, mas de atualidade e relevância perenes e recorrente, como é o caso da liberdade religiosa, pois é um tema multidimensional e desafia múltiplas abordagens.

Impende consignar que a exteriorização da fé religiosa, no entrechoque das ideias e das opiniões difundidas no ambiente do trabalho, vez por outra se apresenta amalgamada com algum nível de intolerância que compromete o diálogo e a convivência entre empregados e entre estes e o seu empregador.

As situações conflituosas com viés religioso que podem ocorrer no ámbito da relação de emprego são muitas, como por exemplo, problemas de colisão de direitos no local de trabalho, nos domínios da liberdade e da não discriminação, do uso de símbolos religiosos, do proselitismo ou do assédio moral e religioso.

A tentativa de resolvê-las reclamam esforço para superá-las, pois a acomodação das práticas religiosas ao ambiente do trabalho testa a capacidade dos atores da relação de emprego, entre empregadores e empregados, de conviver com o pluralismo e sob tal perspectiva, implica um desafio multicutural que pode ser tomado como importante critério para a aferição da qualidade de democracia suportada pelo todo social.

Nesse sentido, o presente artigo se propôs a analisar a liberdade religiosa e os conflitos religiosos no ambiente de trabalho dentro de uma perspectiva do direito do trabalho.

Por fim, o presente artigo arranca uma abordagem geral competente e bem articulada em termos dogmáticos, para depois trilhar uma perspectiva mais concreta, identificando os principais pontos da conexão entre a liberdade religiosa e os contratos de trabalho e não descurando de avaliar a sua particular configuração, identificando as tensões ali processadas e as possíveis soluções, assumindo nesse contexto um tom saudavelmente propositivo e transformando o artigo em uma ferramenta útil não apenas aos que, no plano académico, se debruçam sobre os meandros da liberdade religiosa, mas que na prática se dedicam à sua aplicação aos casos da vida. 


\section{NOÇÕES SOBRE LIBERDADE RELIGIOSA}

A liberdade religiosa surgiu durante os séculos XVI e XVII, com a ideia de que o sagrado é inerente ao ser humano e foi erigida com o equilíbrio das influências iluministas e cristãs.

Segundo Jónatas E. M. Machado:

O processo de fundamentalização do direito à liberdade religiosa iniciou-se com a Reforma Protestante, as guerras religiosas e o surgimento de pequenos grupos de puritanos evangélicos radicais. Estes acontecimentos estão na base do esforço teorético-político para a estruturação do discurso político em bases racionais, estabelecendo os alicerces, primeiramente da tolerância e depois da liberdade religiosa. (MACHADO, 2003, p. 78)

Ademais, inúmeras concepções foram construídas ao longo da história acerca do tema, conforme as diversas correntes filosóficas. Para a corrente jus naturalista, a liberdade religiosa é direito natural da pessoa humana, que nasce com o homem, que é ser ontologicamente livre. Todavia, para os idealistas, a liberdade religiosa é um ideal e para os realistas, se traduz na conquista humana, consubstanciada nos instrumentos jurídicos internacionais e nacionais de direitos humanos, conforme dispõe, por exemplo, a Declaração Universal dos Direitos Humanos, apresentada em 1948, que prevê no seu preâmbulo e no seu artigo XVIII que:

[...] o desprezo e o desrespeito pelos direitos humanos resultaram em atos bárbaros que ultrajaram a consciência da Humanidade e que o advento de um mundo em que os homens gozem de liberdade de palavra, de crença e da liberdade de viverem a salvo do temor e da necessidade foi proclamado como a mais alta aspiração do homem comum.

Art. XVIII - Toda pessoa tem direito a liberdade de pensamento, consciência e religião, este direito inclui a liberdade de mudar de religião ou crença e a liberdade de manifestar essa religião ou crença, pelo ensino, pela prática, pelo culto e pela observância, isolada ou coletivamente, em público ou em particular (ASSEMBLÉIA GERAL DAS NAÇÕES UNIDAS, Declaração Universal dos Direitos Humanos, 1948).

Esta definição da Declaração é muito importante, pois, apesar de ter caráter meramente declaratório, esclarece que a liberdade religiosa implica na liberdade de crença, de culto, conversão de religião ou crença e a liberdade de manifestar essa religião ou crença, é exercida pelo ensino, pela prática, pelo culto e pela observância, isolada ou coletivamente, em público ou em particular. 
Outros instrumentos jurídicos internacionais de grande influência foram discutidos e assinados por representantes de várias nações e culturas ao redor do mundo, como por exemplo, os Pactos de 1966, denominados de Pacto Nacional sobre Direitos Civis e Políticos e o Pacto Internacional sobre Direitos Científicos, Sociais e Culturais.

Para Bobbio (2000, p. 57), a liberdade religiosa e de manifestação de opinião é uma "exigência que deriva da tomada de consciência da irredutibilidade das opiniões e da necessidade de se encontrar um modus vivendi que permita a todos externar as suas visões”.

No entanto, esse modus vivendi só será possível quando houver uma convivência pacífica pelo compromisso da não imposição de uma única verdade, pois ao ser humano cabe o direito de escolha, desde que não prejudique o outro.

Nas palavras de Soriano (2009, p.09) "o ser humano tem o direito de escolher as suas crenças e de viver ou não de acordo conforme os ditames de sua consciência religiosa, ateia ou agnóstica".

Ademais, ninguém pode ser forçado a seguir determinada religião, pois isso se chama manipulação e o ser humano deve ter como garantia o livre arbítrio, porque ao contrário, o deixa de ser dotado de dignidade própria.

Em consonância com o discurso acima, Jónatas E. M. Machado afirma:

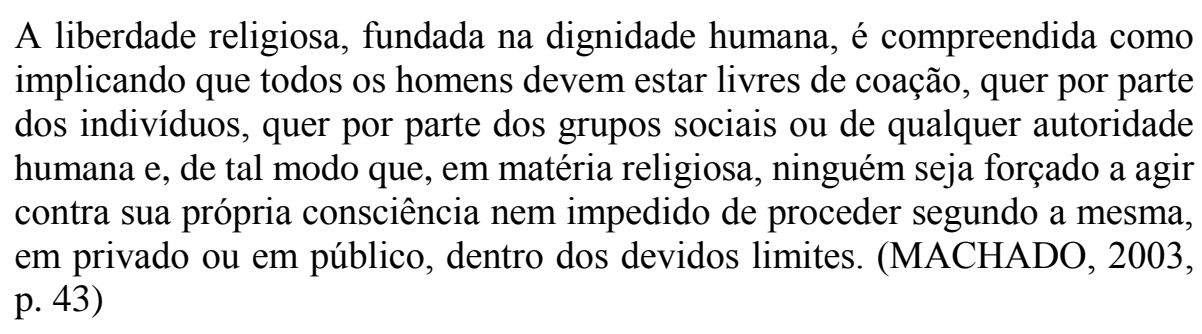

Em razão disto, os Estados bem como os indivíduos têm obrigação de respeitar e garantir o espaço de crença-religiosa dos cidadãos estabelecido pelas normas internacionais, tais como os limites legais para proteger a vida ou segurança das pessoas. Isso inclui o direito de manifestar uma religião ou crença seja de maneira individual ou coletiva. Portanto, o direito de ter ou não religião, sem a interferência ou restrição governamental é um fundamento essencial para a dignidade humana.

Neste contexto, apura-se que a liberdade religiosa está intrinsecamente relacionada ao princípio da tolerância religiosa, pois segundo Noberto Bobbio: 
Quem percorreu a historia da liberdade religiosa sabe que, em seu nascimento, nos séculos XVI e XVII, a ideia da tolerância não foi um produto da indiferença religiosa, mas, quando muito, de uma fé não imposta, mas livremente professora. (...)

Foi preciso a liberdade de fé ou de opinião, assegurada por uma correta aplicação da regra da tolerância, para que passasse a ser reconhecido como a melhor condição para fazer que, mediante a persuasão e não a imposição triunfe a verdade em que se crê. (BOBBIO, 2000, p. 137, 151)

Levando em consideração o princípio da tolerância juntamente com o da liberdade religiosa, afere-se que ambos são fundados no reconhecimento das liberdades fundamentais e na dignidade humana, não podendo utilizar a violência para justificar qualquer lesão a tais princípios.

Jonh Locke (2005, p. 25) na sua obra Cartas sobre a tolerância de 1689 acrescenta que “não é a diversidade de opiniões (o que não pode ser evitado), mas a recusa de tolerância para com os que têm opinião diversa, o que se poderia admitir que deu origem a maioria das disputas e guerras".

É oportuno ressaltar que a Declaração de Princípios sobre a Tolerância, aprovada pela Conferência Geral da UNESCO em sua $28^{\mathrm{a}}$ reunião em Paris, em 16 de novembro de 1995 e a Declaração sobre a eliminação de todas as formas de intolerância e discriminação fundadas na religião ou nas convicções de 1981 consideraram que a religião ou as convicções, para quem as profere, constituem um dos elementos fundamentais em sua concepção de vida e que, portanto, a liberdade de religião ou de convicções devem ser integralmente respeitadas e garantidas.

Neste sentido, impende consignar o conceito de tolerância apresentado pela Declaração de Princípios sobre a Tolerância no seu artigo $1^{\circ}$ :

A tolerância é o respeito, a aceitação e o apreço da riqueza e da diversidade das culturas de nosso mundo, de nossos modos de expressão e de nossas maneiras de exprimir nossa qualidade de seres humanos. É fomentada pelo conhecimento, a abertura de espírito, a comunicação e a liberdade de pensamento, de consciência e de crença. A tolerância é a harmonia na diferença. Não só é um dever de ordem ética, é igualmente uma necessidade política e jurídica. A tolerância é uma virtude que torna a paz possível e contribui para substituir uma cultura de guerra por uma cultura de paz. A tolerância é, antes de tudo, uma atitude fundada no reconhecimento dos direitos universais da pessoa humana e das liberdades fundamentais do outro. Em nenhum caso a tolerância poderia ser invocada para justificar lesões a esses valores fundamentais. A tolerância deve ser praticada pelos indivíduos, pelos grupos e pelo Estado. (Declaração de Princípios sobre a Tolerância, 1995). 
Em consonância ao respeito aos direitos humanos, praticar a tolerância não significa tolerar a injustiça social, nem renunciar às próprias convicções, nem fazer concessões a respeito. A prática da tolerância significa que toda pessoa tem a livre escolha de suas convicções e aceita que o outro desfrute da mesma liberdade. Significa aceitar o fato de que os seres humanos, que se caracterizam naturalmente pela diversidade de seu aspecto físico, de sua situação, de seu modo de expressar-se, de seus comportamentos e de seus valores, têm o direito de viver em paz e de ser tais como são. Significa também que ninguém deve impor suas opiniões a outrem.

Vale ressaltar que foi aprovada por unanimidade por parte do Congresso Americano a Lei sobre Liberdade Religiosa Internacional em 1998 e tem por objetivo fazer um levantamento da liberdade e restrição religiosa em 198 países e territórios, fornecendo informações adicionais detalhadas com relação às questões que envolvem a liberdade religiosa internacional. Conforme este relatório, o fato da grande maioria da população mundial professar alguma crença ou ter algum identificação religiosa, faz nascer o direito de liberdade religiosa, pois, além de ser um fundamento essencial para a dignidade humana, é também para uma sociedade civil robusta e para a democracia sustentável.

Ademais, entende o relatório supracitado, que a liberdade religiosa tende a canalizar as convicções e as paixões da fé em atos de contribuição e participação na esfera pública, ajudando na estabilidade nacional e segurança internacional.

É necessário o reconhecimento da liberdade religiosa por todas as sociedades e por todos os governos para que os indivíduos de qualquer natureza, raça, nação, em especial as minorias religiosas, possam ter a liberdade de professar, praticar e propagar a fé, de outra forma, ela estará sendo refutada.

É possível estimular a retórica com base na diversidade religiosa e na tolerância. Os discursos, a música, a arte e a poesia ilustram de que modo uma linguagem persuasiva pode ajudar as pessoas a imaginar a igualdade e ver as diferenças como algo desejável e não algo a ser temido. 


\section{DISCRIMINAÇÃO NO AMBIENTE DE TRABALHO}

Quando se fala em discriminação, logo vem à mente o sentido de separar, não se misturar, segregação de grupos, etc. Mas é preciso fazer uma análise jurídica do termo “discriminar" para uma melhor compreensão de sua aplicação no âmbito do direito, pois a própria Constituição Federal apresenta algumas situações de discriminação.

Em primeiro lugar, a Constituição Federal, em seu art. $5^{\circ}$, caput, estabelece o princípio da igualdade, e em várias ocasiões permite a discriminação para que seja praticada a igualdade material, nesse contexto surge a necessidade de esclarecimento entre a discriminação negativa e positiva.

Terminantemente a Constituição Federal proíbe a discriminação negativa ou ilícita, pois há sempre um tratamento desigual em desfavor do cidadão, no qual são negados os exercícios dos direitos fundamentais, segregando-o ou excluindo-o do seio da sociedade. São práticas discriminatórias injustificadas.

Para Cruz (2011, p.29) “a discriminação ilícita é uma conduta humana (ação ou omissão) que viola os direitos das pessoas com base em critérios injustificados e injustos, tais como raça, o sexo, a idade, a opção religiosa e outros".

De outro lado, há situações nas quais se faz necessário criar uma distinção ou uma desigualdade para que se possa atender o princípio da isonomia e o da dignidade da pessoa humana, operando-se, assim, uma discriminação in bonan parte ou positiva.

Para Coutinho a discriminação positiva:

[...] é um modo de eliminar as diferenças, ao assegurar a igualdade de oportunidades a todos, mediante políticas protetivas ou distributivas de benefícios às pessoas ou grupos que se encontram em situação desfavorável, com o objetivo de corrigir os desequilíbrios existentes na sociedade. Justiçase a discriminação positiva a partir da ideia de equidade, que vai dizer da necessidade de tratamento igual para os iguais e desigual para os desiguais (COUTINHO, 2006, p. 14).

A partir da visão de discriminação positiva é que surgem as ações afirmativas, pois visam garantir a igualdade de oportunidade e de tratamento aos cidadãos.

Feitas essas considerações, apenas nos ocuparemos com a discriminação ilícita ou negativa no ambiente de trabalho, a qual precisa ser combatida.

No âmbito internacional a definição de discriminação é tratada pelo art. $1^{\mathrm{o}}$ da Convenção no 111 da Organização Internacional do Trabalho: 
Art. 1. Para os fins da presente convenção o termo discriminação compreende: toda distinção, exclusão ou preferência fundada na raça, cor, sexo, religião, opinião política, ascendência nacional ou origem social, que tenha por efeito destruir ou alterar a igualdade de oportunidade ou de tratamento em matéria de emprego ou profissão (CONVENÇÃO no 111 da ORGANIZAÇÃO INTERNACIONAL DO TRABALHO).

Por sua, a Convenção no 158 da OIT, apesar da divergência quanto a sua eficácia no território brasileiro, veda, também, em seu art. $5^{\circ}$, a dispensa do trabalhador por seguintes motivos: raça, cor, sexo, o estado civil, as responsabilidades familiares, a gravidez, a religião, as opiniões políticas, ascendência nacional ou a origem social.

No âmbito nacional, a Constituição, em seu art. $3^{\circ}$, inciso IV, constituiu como um dos objetivos da República Federativa do Brasil a promoção do bem de todos, sem preconceitos de origem, raça, sexo, cor, idade e quaisquer outras formas de discriminação.

E ainda, o constituinte garantiu isonomia e proibição de discriminação na relação de trabalho, especificamente no art. $7^{\circ}$, que pró́be diferença de salários, de exercício de funções e de critérios de admissão por motivo de sexo, idade, cor ou estado civil (inciso XXX); proíbe qualquer discriminação no tocante a salário e critério de admissão do trabalhador portador de deficiência (inciso XXXI); assim como estabelece a igualdade de direitos entre o trabalhador com vínculo empregatício e o trabalhador avulso (inciso XXXIV).

Na esfera infraconstitucional, a Lei no 9.029/1995, também veio reforçar a proteção do trabalhador na relação de emprego, inadmitindo qualquer tipo de prática discriminatória por parte do empregador, in verbis:

Art. $1^{\circ}$ Fica proibida a adoção de qualquer prática discriminatória e limitativa para efeito de acesso à relação de emprego, ou a sua manutenção, por motivo de sexo, origem, raça, cor, estado civil, situação familiar ou idade, ressalvadas, neste caso, as hipóteses de proteção ao menor prevista no inciso XXXIII do art. $7^{\circ}$ da Constituição Federal.

Observa-se que, tanto nas legislações no âmbito internacional quanto nacional, o objetivo é erradicar toda forma de discriminação, a fim de promover a igualdade material entre os trabalhadores.

E é na relação de trabalho que mais surgem casos de discriminações ilícitas, seja no momento da contratação, na relação de emprego ou na dispensa do empregado, e isso ocorre em razão do poder diretivo do empregador. 
Brito Filho (2002, p. 101) entende que discriminar, em matéria de trabalho, é "negar ao trabalhador a igualdade necessária que ele deve ter em matéria de trabalho, é negar ao trabalhador a igualdade necessária que ele deve ter em matéria de aquisição e manutenção do emprego, pela criação de desigualdades entre pessoas".

Sarlet ensina que:

Constitui pressuposto essencial para o respeito da dignidade da pessoa humana a garantia da isonomia de todos os seres humanos, que não podem ser submetidos a tratamento discriminatório e arbitrário, razão pela qual são intoleráveis a escravidão, a discriminação racial, perseguição em virtude de motivos religiosos, etc. (SARLET, 2007, p. 110).

Aliás, tem-se que combater qualquer norma interna da empresa, que apesar de ser considerada neutra na aplicação entre os funcionários, pode trazer uma discriminação indireta na medida em que coloca os trabalhadores em desvantagens entre si no exercício de suas liberdades individuais.

\section{ASSÉDIO MORAL POR RAZÕES RELIGIOSAS E ASSÉDIO RELIGIOSO}

O assédio moral por razões religiosas, nada mais é do que uma discriminação religiosa exacerbada. Neste sentido, o assédio moral é motivado pela intolerância

religiosa e vincula-se mais estreitamente ao problema da discriminação religiosa no ambiente de trabalho.

$\mathrm{Na}$ visão da Comissão para a igualdade de oportunidades e emprego, o assédio moral por razões religiosas ocorre quando o empregado é instado ou coagido a abandonar, alterar ou adotar uma prática religiosa como uma condição para a obtenção ou manutenção do emprego (por exemplo, por meio de um tratamento desigual ou eventualmente pela negação da acomodação de suas práticas religiosas) ou é submetido a comentários ou a ações desagradáveis, motivadas por razões religiosas, cuja gravidade ou generalização justifique que o indivíduo assediado considere o ambiente de trabalho hostil ou abusivo e haja fundamento para a responsabilização do empregador.

Impende consignar que o que distingue assédio moral por razões religiosas do assédio moral no trabalho é tão somente o móvel de conduta abusiva do agressor, que age motivado pela intolerância à identidade religiosa de sua vítima. As mesmas técnicas utilizadas para 
desestabilizar a vítima em qualquer modalidade de assédio moral também podem ser manejadas quando o motivo da conduta abusiva é a discriminação religiosa.

Vale salientar, que no entendimento majoritário da doutrina e jurisprudência pátria, nem toda discriminação religiosa será assédio moral. Para que este configure faz- se necessário que a conduta discriminatória seja reiterada, tenha como finalidade a exclusão da vítima e cause um dano à sua integridade psicofísica.

Assim, é possível compreender o assédio moral por razões religiosas como uma discriminação religiosa qualificada pela reiteração de condutas ofensivas à dignidade da vítima, com o objetivo de trazer-lhe danos à integridade psicofísica e assim, afastá-la do ambiente de trabalho.

O assédio moral por razões religiosas praticadas pelo empregado contra colegas de trabalho e contra terceiros (clientes, fornecedores) pode configurar o mau procedimento e consequentemente a justa causa para a rescisão de contrato de trabalho pelo empregador tipificada na alínea b do art. 482 da CLT.

No tocante a reparação do dano moral, o assédio moral por razões religiosas por afetar diretamente algumas das mais sagradas projeções da personalidade, a exemplo da consciência, da integridade psíquica e da autoimagem, inevitavelmente causa um prejuízo moral, que deve ser, por um princípio de equidade, adequadamente compensado.

Por outro lado, no assédio religioso o sujeito ativo tenta de forma insistente converter alguém a sua crença. A expressão assédio religioso deve ser utilizada para designar não o simples abuso na prática do proselitismo religioso, mas um abuso qualificado por uma repetição ou sistematização da conduta proselitista que atente contra a liberdade de consciência de uma pessoa, causando transtornos a integridade psíquica da vítima ou degradando o ambiente de trabalho.

É importante destacar que o assédio religioso somente pode ter como sujeito ativo um indivíduo religioso. Por outro lado, o assédio moral por razões religiosas, pode ter como sujeito ativo um indivíduo religioso, não religioso ou antirreligioso.

Outra diferença no tocante ao assédio moral por razões religiosas é que uma pessoa, apenas em virtude de professar sua crença, mesmo que não se entregue a pratica de proselitismo, é sistematicamente alvo de gestos, palavras, comportamentos e atitudes ofensivas à sua dignidade ou integridade psicofísica. Por exemplo, o comportamento reiterado de algum colega do trabalho contra um trabalhador evangélico chamando-o de alienado por entregar o seu dinheiro mensalmente a pastores ladrões configura assédio moral por razões religiosas. 
Por outro lado, o simples convite para participar de uma religião, ainda que mais de uma vez, sem que tenha atentado contra a integridade psicofísica do trabalhador, ameaçado seu emprego ou degradado o clima de trabalho, não configura assédio religioso.

Os efeitos jurídicos no caso do assédio religioso pode se configurar a justa causa na conduta de mau procedimento, desídia e indisciplina ou insubordinação. Já a reparação por dano moral, segundo Santos Júnior (2013, p. 58) "uma das situações que mais retratam o sofrimento moral é justamente o assédio religioso no trabalho", que ocorre quando a conduta do proselitista interfere além dos limites do razoável no desempenho laboral de um trabalhador, podendo inclusive, fazer com que este venha a cometer erros que resultem na perda do emprego.

No que diz respeito ao uso de signos de identificação religiosa, é razoável entender que o uso de adereços religiosos deve ser permitido, uma vez que, não implicando qualquer ônus para o empregador, compreende-se no dever patronal de acomodar as práticas religiosas dos empregados que não interfiram no desenvolvimento das atividades estatais.

Mais do que manifestação da liberdade de expressão, porém, o uso de adereços religiosos configura uma posição jurídica que integra a liberdade religiosa, a liberdade de expressão e a liberdade de autodeterminação da imagem, representando um caso típico de concorrência de direitos fundamentais.

A vedação pelo empregador do uso de signos pessoais religiosos discretos presume-se discriminatória. É razoável que nas situações que ponham em risco a integridade física do trabalhador ou do cliente e à eficiência da atividade profissional, o uso de adereços deve ser vedado, não propriamente pelo caráter religioso, mas por razões de ordem técnica, sanitária ou de segurança que justifiquem a imposição de um vestuário especifico.

É necessário buscar por meio da ponderação o justo equilíbrio entre um direito fundamental do trabalhador de manifestar a sua fé religiosa e a política patronal de uniformização do funcionário.

Os casos mais reportados pela mídia e pelos tribunais europeus referem-se ao uso dos lenços e do véu islâmico. Para alguns adeptos de cultos afro-brasileiros vestirem-se de branco em uma sexta-feira é uma praxe religiosa observada por muitos indivíduos onde o candomblé é praticado. Os judeus ortodoxos costumam ter sobre a cabeça um solidéu - quipá.

Se o empregador não estabelece a obrigatoriedade do uso de uniforme por seus empregados, em regra, será permitido o uso de indumentárias com conotação religiosa, pois a interferência no modo de vestir dos trabalhadores por razões puramente estéticas não deve ser considerada suficiente. 
É certo que em algumas situações não haverá como assegurar ampla liberdade ao empregado na escolha do vestuário, porque a natureza da profissão exige a utilização de trajes específicos, como é o caso dos atletas profissionais e dos tripulantes de aeronaves.

No caso dos futebolistas no âmbito nacional, a restrição somente será razoável se fundamentada num encargo desproporcional ao clube, por exemplo, causando-lhes danos a sua imagem ou ao seu patrimônio. No fundo, a problemática se resolve mesmo é com o uso do critério da proporcionalidade. A restrição para ser valida precisa ser adequada, necessária e proporcional em sentido estrito.

Como o objetivo deve ser tão somente evitar os excessos que caracterizariam a abusividade do proselitismo religioso e causariam prejuízos morais ou materiais ao clube, não parece concebível no contexto brasileiro que se desconsidere necessária a vedação total a expressão religiosa como forma de combate ao proselitismo abusivo.

\section{ATOS DE CULTO NO AMBIENTE DE TRABALHO}

Há empregadores que costumam realizar diariamente cultos ou orações nos seus estabelecimentos empresariais. A ilicitude está em querer forçar por qualquer meio a participação do empregado. Tal constrangimento é inaceitável porque viola a liberdade de consciência do trabalhador e, portanto afronta a sua dignidade. Até porque, a adesão religiosa só é legitima quando voluntaria.

A história muda de figura, contudo, se a organização empresarial é de tendência religiosa, pois se presumirá que o culto integra as suas finalidades e, portanto, poderá constituir um serviç̧o.

O problema adquire maior complexidade quando a religião do empregado impõe a interrupção da atividade laborativa em períodos determinados ao longo do dia para a prática de atos de culto. É o que se da, por exemplo, com a religião islâmica. Em tais situações será necessário levar em considerações diversas circunstancias na tentativa de estabelecer se possível ao empregador acomodar a prática religiosa do empregado.

Mas muitas dificuldades podem se apresentar a acomodação, ligadas à natureza desenvolvida pelo empregador ou ao serviço contratado pelo empregado. Certas funções que exigem trabalho ininterrupto e atenção máxima durante toda a jornada como é o caso dos vigilantes. 
Há atos de culto por traduzirem gestos rápidos e discretos, mesmo quando praticados durante o tempo de trabalho, passam despercebidos e não chegam a causar prejuízo a atividade laboral, como por exemplo, o habito de fazer o sinal da santa cruz. Gestos como esse, em principio, não são abusivos.

\section{A OBJEÇÃO DE CONSCIÊNCIA PROFISSIONAL POR RAZÕES RELIGIOSAS E DIAS DE GUARDA}

Os profissionais de saúde estão suscetíveis a enfrentar intrincadas questões éticas que lidam diariamente com a vida humana. As questões polêmicas geralmente giram em torno do aborto, a eutanásia e a hemotransfusão que são situações paradigmáticas.

A transfusão de sangue é uma pratica pela doutrina das testemunhas de Jeová, o que levanta a questão sobre a possibilidade de que profissionais de saúde adeptos da religião oponham objeção de consciência quando lhes for exigida a participação nesse método terapêutico.

Como a colisão da liberdade religiosa do profissional de saúde com o direito a vida, cuja precedência deve ser reconhecida enquanto pressuposto a fruição dos demais direitos fundamentais são de exigir, com base no princípio da boa-fé que o candidato ao emprego não omita a sua condição religiosa, independentemente de que lhe seja perguntada ou não, quando a natureza do serviço a ser prestado implique, mesmo que em caráter eventual, a realização de transfusão de sangue.

Todavia, se o profissional de saúde testemunha de Jeová age de boa-fé informando a sua condição religiosa, e a atividade empresarial permite a utilização de seus serviços em outros setores, sem prejuízo para os negócios do empregador, este deverá acomoda-lo sob pena de ficar caracterizada a discriminação religiosa.

Com relação aos professores, a questão que se coloca tem a ver não apenas com os limites da liberdade religiosa do professor em sala de aula, mas também da liberdade que se reconhece a escola confessional de transmitir, juntamente com o conteúdo oficial, os valores ético-religiosos em que se funda.

Olhando a questão sob a perspectiva da escola confessional, desde que os conteúdos mínimos fixados pelo estado sejam observados, não haverá qualquer óbice a que a instituição também procure transmitir aos seus alunos os valores ético-religiosos que orientam a sua fundação. Sua condição de organização de tendência confessional justifica que exija de seus 
empregadores professores uma adesão aos princípios éticos de base religiosa que busca preservar e divulgar.

No tocante a guarda de dias santos, o domingo como dia preferencial de descanso remunerado foi escolhido em atenção à tradição católica do povo brasileiro. O labor nesse dia, nos termos do art. 58 da CLT, demanda previa permissão do ministério do trabalho e emprego. Os feriados que podem ser instituídos pela legislação federal ou municipal, incluem não apenas datas comemorativas cívicas, mas também dias de guarda prescritos pela religião católica, como a sexta-feira santa, o Corpus Christi, o natal, o dia de finados e o mais recente e polêmico, o dia da padroeira do brasil.

\section{CONSIDERAÇÕES FINAIS}

A liberdade religiosa ainda traz muitos conflitos na seara trabalhista, especialmente sobre a possibilidade de se impor limites no gozo pleno desse direito. No contexto brasileiro, é necessário o reconhecimento de um dever empresarial de acomodação das práticas religiosas dos empregados à semelhança do que ocorre no direito estadunidense.

Tanto a Constituição quanto as leis internacionais e nacionais são enfáticas ao proibir qualquer tipo de discriminação que desqualifique a pessoa como ser humano, negando-lhe os seus direitos fundamentais. E do mesmo modo, o empregador não pode praticar atos discriminatórios contra o trabalhador em razão de sua crença, na fase pré-contratual, exigindo informações íntimas do candidato, salvo nas instituições em que a atividade fim é propagar a sua ideologia, seja na recusa de participar de orações diárias da empresa ou simplesmente professar ou não a sua fé no ambiente de trabalho.

A liberdade religiosa do empregado deve ser garantida no ambiente de trabalho, porém ela pode sofrer algumas restrições na sua prática, a depender da função ou do serviço contratado na atividade finalística do empregador. O caso concreto, ao ser analisado os conflitos com viés religioso no ambiente de trabalho deve sempre levar em consideração os mesmos mecanismos que a dogmática dos direitos fundamentais disponibiliza para a resolução das colisões de direitos fundamentais, incluindo-se a técnica da ponderação com a utilização dos critérios da proporcionalidade e da razoabilidade.

Impende ainda consignar, que o abuso no exercício da liberdade religiosa, parta do empregado ou empregador, pode redundar em justa causa resilitória do contrato de trabalho e em dano moral a ser composto mediante pagamento de indenização. 
Por fim, a defesa da liberdade religiosa pode ser exercida pelo trabalhador, pelo Sindicado e pelo Ministério Público do Trabalho perante a Justiça do Trabalho, por meio de ações indenizatórias, ações cominatórias e ações civis públicas.

\section{REFERÊNCIAS BIBLIOGRÁFICAS}

BOBBIO, Noberto. A Era dos direitos. $4^{\mathrm{a}}$ reimpressão, Tradução de Carlos Nelson Coutinho. Rio de Janeiro: Editora Campus, 2000.

BRITO FILHO, José Cláudio Monteiro de. Discriminação no trabalho. São Paulo: LTr, 2002.

COUTINHO, Maria Luiza Pinheiro. Discriminação no trabalho: mecanismos de combate e de promoção da igualdade de oportunidades. Brasília: OIT, 2006.

CRUZ, Álvaro Ricardo de Souza. O direito à diferença: as ações afirmativas como mecanismo de inclusão social de mulheres, negros, homossexuais e portadores de deficiência. $3^{a}$ ed. Belo Horizonte: Del Rey, 2011.

DRAY, Guilherme Machado. O princípio da igualdade no direito do trabalho: sua aplicabilidade no domínio específico da formação de contratos individuais de trabalho. Coimbra: Livraria Almedina, 1999.

GONÇALVES, Rogério Magnus Varela. Direito constitucional do trabalho: aspectos controversos da automatização. Porto Alegre: Livraria do Advogado Editora, 2003.

LOCKE, John. Carta acerca da tolerância. Segundo tratado sobre o governo. Ensaios acerca do entendimento humano. São Paulo: Martin Claret, 2005.

MACHADO, Jônatas E. M. Liberdade religiosa numa comunidade constitucional inclusiva. Coimbra: Coimbra Editora, 2003.

MORAES, Alexandre de. Direitos humanos fundamentais: teoria geral, comentários aos $\operatorname{artigos} 1^{\circ}$ ao $5^{\circ}$ da Constituição da República Federativa do Brasil, doutrina e jurisprudência. $6^{\mathrm{a}}$ ed. São Paulo: Atlas, 2005.

OLIVEIRA, Erival da Silva. Direitos humanos. São Paulo: Editora Revista dos Tribunais, 2009.

PIOVESAN, Flávia. Temas de direitos humanos. $3^{\text {a }}$ ed. São Paulo: Saraiva 2009. 
Direitos humanos e o direito constitucional internacional. 3a ed. São Paulo: Max Limonad, 1997.

RIBEIRO, Marcus Vinicius. Direitos humanos e fundamentais. $2^{\mathrm{a}}$ ed. Campinas: Russell Editores, 2009.

RODRIGUES, Simone Martins. Segurança internacional e direitos humanos: a prática da intervenção humanitária de pós-guerra fria. Rio de Janeiro: Renovar, 2000.

SILVA, Marco Antônio Marques. O acesso à justiça e o estado democrático de direito. São Paulo: Saraiva, 2006.

SARLET, Ingo Wofgang. A dignidade da pessoa humana e direitos fundamentais. $6^{\mathrm{a}}$ ed. ver. atual. e ampl. Porto Alegre: Livraria do Advogado Editora, 2007.

A eficácia dos direitos humanos fundamentais. $6^{a}$ ed. ver. atual. e ampl. Porto Alegre: Livraria do Advogado Editora, 2007.

TOSI, Giuseppe (org.). Direitos Humanos: história, teoria e prática. João Pessoa: Universitária / UFPB, 2005.

SANTOS JÚNIOR, Aloisio Cristovam dos. Liberdade religiosa e contrato de trabalho: a dogmática dos direitos fundamentais e a construção de respostas constitucionalmente adequadas aos conflitos religiosos no ambiente de trabalho. Niterói: Impetus, 2013.

SORIANO, Aldir Guedes. Universalidade dos direitos humanos e liberdade religiosa. Revista Consulex. Ano XIII, nº. 298, de 15 de Junho de 2009.

VARELLA, Marcelo Dias. Direito internacional público. 2a ed. São Paulo: Saraiva, 2010. 